\title{
Socio-economic differences in the uptake of HIV testing and associated factors in South Africa
}

Sean Jooste ${ }^{1,2^{*}}$, Musawenkosi Mabaso ${ }^{1}$, Myra Taylor ${ }^{2}$, Alicia North ${ }^{1}$, Yolande Shean ${ }^{1}$ and Leickness Chisamu Simbayi ${ }^{3,4}$

\begin{abstract}
Background: Improved understanding of barriers to HIV testing is important for reaching the first of the UNAIDS 90-90-90 targets, which states that 90\% of HIV positive individuals ought to know their HIV status. This study examined socio-economic status (SES) differences in HIV testing uptake and associated factors among youth and adults 15 years and older in South Africa.
\end{abstract}

Methods: This study used data from a national cross-sectional, population-based household survey conducted in 2017 using a multi-stage sampling design. A composite SES score was created using multiple correspondence analyses of household assets; households were classified into wealth quintiles and dichotomised into low SES/ poorest (lowest 3 quintiles) and high SES/less-poor (highest 2 quintiles). Bivariate and multivariate logistic regression models were used to examine factors associated with the uptake of HIV testing in low and high SES households.

Results: HIV testing uptake was 73.8 and $76.7 \%$ among low and high SES households, respectively, both of which were below the first 90 targets. Among both low and high SES households, increased HIV testing uptake was significantly associated with females than males. The decreased likelihood was significantly associated with residing in rural formal areas than urban areas, those with no education or low levels of educational attainment and alcohol drinkers among low SES households. Whites and Indians/Asians had a decreased likelihood than Black Africans in high SES households.

Conclusions: HIV testing interventions should target males, residents in rural formal areas, those with no or low education and those that consume alcohol in low SES households, including Whites and Indians/Asians from high SES households in order to bridge socio-economic disparities in the uptake of HIV testing. This should entail expanding HIV testing beyond traditional centres for voluntary counselling and testing through outreach efforts, including mobile testing and home-based testing.

Keywords: UNAIDS 90-90-90 targets, HIV testing, Socio-economic status, South Africa

\footnotetext{
* Correspondence: sjooste@hsrc.ac.za

${ }^{1}$ Human and Social Capabilities Research Division, Human Sciences Research

Council, 118 Buitengracht St, Cape Town City Centre, Cape Town 8000,

South Africa

${ }^{2}$ University of KwaZulu-Natal, School of Nursing and Public Health, 238 Mazisi

Kunene Rd, Glenwood, Durban 4041, South Africa

Full list of author information is available at the end of the article
}

(c) The Author(s). 2021 Open Access This article is licensed under a Creative Commons Attribution 4.0 International License, which permits use, sharing, adaptation, distribution and reproduction in any medium or format, as long as you give appropriate credit to the original author(s) and the source, provide a link to the Creative Commons licence, and indicate if changes were made. The images or other third party material in this article are included in the article's Creative Commons licence, unless indicated otherwise in a credit line to the material. If material is not included in the article's Creative Commons licence and your intended use is not permitted by statutory regulation or exceeds the permitted use, you will need to obtain permission directly from the copyright holder. To view a copy of this licence, visit http://creativecommons.org/licenses/by/4.0/. The Creative Commons Public Domain Dedication waiver (http://creativecommons.org/publicdomain/zero/1.0/) applies to the data made available in this article, unless otherwise stated in a credit line to the data. 


\section{Background}

Sub-Saharan Africa (SSA) bears the largest burden of the HIV epidemic, with $53 \%$ of the world's 36.9 million [31.1-43.9 million] people living with HIV in 2018 [1]. The HIV epidemic in South Africa is the largest globally, with a national prevalence of $14 \%$, which translated to an estimated 7.9 million people living with HIV in 2017 [2]. HIV testing uptake serves as the foundation for the Joint United Nations Programme on HIV/AIDS (UNAIDS) strategic framework in the fight against HIV [3]. This framework specifies that $90 \%$ of HIV-positive people should be aware of their status, $90 \%$ of those diagnosed should receive sustained antiretroviral therapy (ART), and $90 \%$ of those on ART achieve viral suppression [3]. This framework was adopted in December 2014 by the South African government as the basis of its national response to the HIV/AIDS epidemic in the country. Achieving the UNAIDS and South African government targets hinges on reaching the key goal of identifying $90 \%$ of people living with HIV in order to start the treatment continuum.

HIV testing is crucial as it provides a diagnosis for people living with HIV for linkage to care and treatment [4]. Globally, progress is being made, and at the end of 2017, three-quarters of people living with HIV knew their status [1]. Despite the excellent strides made with HIV testing in SSA, awareness of HIV status remains lower than the rest of the world. Findings from 10 population-based studies in 2012 identified that the average percentage of people living with HIV who know their status was below 40\% [5]. Several barriers to HIV testing have been identified in studies that have been done in SSA. In the 2005 Demographic and Health Survey in Cote d'Ivoire, a low socio-economic status was related to lower proportions of individuals testing for HIV testing [6, 7]. A multi-country study in Africa found that an increased probability of HIV testing was associated with higher SES [8]. In South Africa, a nationally representative survey found lower HIV testing among people with lower SES [9].

Various socio-economic factors impact HIV testing. For example, educational attainment, employment and income generation have been associated with increased uptake of testing through good access to HIV information and greater control over the decision to test [6-8, 10]. On the other hand, rural settings with widespread poverty have been associated with low HIV testing mainly due to insufficient HIV awareness and knowledge, and logistical constraints such as long travelling distances and affordability of transportation, which lead to poor access to health services and HIV testing [1012]. Other barriers include lower risk perception of HIV infection $[5,7,9,13]$, fear of HIV status and stigma [1315]. These barriers to testing will impede the goal of reaching viral suppression among people living with HIV [3]. Improved understanding of SES related testing barriers may be essential for designing interventions focused on reaching the first 90 targets.

Evidence shows that socio-economic status harms people's wellbeing, especially in settings with widespread poverty and vast income inequality [16]. However, SES is a complex composite measure that typically incorporates social, economic and employment status and is measured by education, income and occupation, respectively [17]. The level of educational attainment may be associated with the type of employment/occupation, better living conditions and health care $[8,18]$. Hence, educational level and inter-related socio-economic measures can sometimes show a weaker or stronger association with deprivation, resulting in a differential relationship with health outcomes than other indices such as wealth and income [17, 19-21].

Income has been the preferred unit of welfare analysis because it is directly comparable among observations, making it straightforward to interpret and use in the quantitative analysis [22, 23]. In the absence of income data, the asset index method is frequently used in many developing countries to complement income measures wealth [24].

This study examines the socio-economic differences in HIV testing uptake and associated factors using data from the 2017 South African national survey in. This survey did not collect data on household income, and this paper used an asset-based measure of SES.

\section{Methods \\ Data}

This study used data from the South African HIV household survey carried out in 2017. The details about the design and sampling of this national survey are given elsewhere [2]. Briefly, a multi-stage stratified random sampling approach was used for selecting residential households within small area layers from a national sampling frame developed by the national statistical agency [25].

Fieldworkers collected data and blood samples from consenting individuals using age-appropriate structured questionnaires [2]. This secondary data analysis focused on respondents 15 years and older who responded to the question on HIV testing. This group has been identified as a priority target for HIV testing services, treatment, and viral load suppression, including HIV prevention efforts.

\section{Primary outcome variable}

The dependent primary outcome variable 'HIV testing' was defined as having accessed HIV testing services at least once before the survey. 
The primary outcome variable was stratified by socioeconomic status, which a composite index was constructed using multiple correspondence analyses (MCA), a data reduction technique for categorical data, based on questions about the presence or absence of basic services and ownership of household assets a binary indicator $[22,23]$. These included ownership of a range of assets (radio, television, landline telephone, washing machine, refrigerator, personal computer/laptop/tablet, solar panel, motor vehicle), housing characteristics (the main source of energy for cooking) and access to basic services (source of drinking water, sanitation facilities, and electricity).

The indicators of asset ownership were organised into a matrix and each asset indicator was decomposed into a set of binary [23]. Then a household composite indicator score was computed by adding up all the weighted responses. The calculation of the household's asset index score can is presented elsewhere [24]. The predicted score for each household was used to compute five wealth quintiles, which were then dichotomised into low SES (lowest 3 quintiles) and high SES (highest 2 quintiles) [26].

\section{Explanatory variables}

Socio-demographic variables included age groups (15-24 years, 25-49 years, and 50 years and older) sex (male and female), racial categories (Black African, White, Coloured, and Indian/Asian), and current marital status (married and not married; which included divorced/separated and widowed/widow), locality type (urban areas formal, rural informal areas, rural formal). Additional variables included the highest educational level completed (no education, primary, secondary, and tertiary) and current employment status (not employed and employed).

Behavioural variables included the age of first sex (having had sex either before or after 15 years of age), age of sexual partner (partner older by 5 years, partner younger by 5 years, a partner within 5 years), number of sexual partners in the last 12 months (one partner, and two or more sexual partners), condom use at last sex (no and yes), alcohol use risk score (abstainers, low, high, and hazardous risk drinkers) based on the Alcohol Use Disorder Identification Test (AUDIT) scale [27, 28], correct HIV knowledge and myth rejection (no and yes) based on responses from the following questions (Can AIDS be cured? Can a person reduce the risk of HIV by having fewer sexual partners? Can a healthy-looking person have HIV? Can a person get HIV by sharing food with someone who is infected? Can a person reduce the risk of getting HIV by using a condom every time he/she has sex?), self-perceived risk of contracting HIV infection (no and yes).

\section{Statistical analysis}

All statistical analysis was done using STATA 15.0 (Stata Corporation, College Station, Texas, USA) software. Pearson's chi-square test was used to compare differences between categorical variables. Comparison of differences in HIV testing between high and low SES in each categorical variable was assessed using a test for two proportions. Bivariate and multivariate logistic regression models were used to examine factors associated with the uptake of HIV testing. The analysis was stratified by asset-based SES yielding two models (low SES model and high SES model). Crude and adjusted odds ratios (aORs) with 95\% confidence intervals (CI) and $p$ values less than 0.05 were reported for all statistically significant associations. Coefficient plots were used to display the results of the final models [29].

\section{Results}

Background characteristics of the study sample

Table 1 shows that over half of the sample was aged 2549 years (53.5\%) and female (52.1\%). The majority were Black African (79.0\%), not married (70.8\%), had completed secondary education (67.6\%) and resided in urban areas (69.5\%). There were significant differences in characteristics between participants with low and high socio-economic status regarding age, race, marital status, level of education, employment status, and locality type $(p<0.001)$.

Table 2 shows socio-demographic characteristics and reported uptake of HIV testing among youth and adults aged 15 years and older by SES. Overall, people with a high SES reported significantly higher HIV testing uptake than those with a low SES, $76.7 \%$ vs $73.8 \%$ ( $p<$ 0.001). HIV testing uptake was significantly higher among people aged 25-49 years, males, Black Africans, the employed, and those residing in rural informal areas in high SES compared to low SES (all $p<0.001$ ). HIV testing uptake was also higher significantly higher among those aged 50 years and older, not married, residing in urban and rural formal areas in high SES compared to low SES (all $p<0.05$ ).

Table 3 shows HIV-related risk characteristics and reported uptake of HIV testing among youth and adults aged 15 years and older by asset-based socio-economic status. HIV testing uptake was significantly higher among those with high SES versus low SES households. It varied significantly by sexual activity, age of sexual partner, alcohol consumption, correct HIV knowledge and myth rejection, self-perceived risk of HIV infection and HIV serostatus (All at $p<0.05$ ).

\section{Factors associated with uptake of HIV testing}

Figure 1 shows the final adjusted models for multivariate logistic regression analysis of predictors of HIV testing 
Table 1 Background characteristics of the sample by socio-economic status (SES) among youth and adults 15 years and older, South Africa 2017

\begin{tabular}{|c|c|c|c|c|c|c|c|}
\hline \multirow[t]{2}{*}{ Variable } & \multicolumn{2}{|c|}{ Overall sample } & \multicolumn{2}{|c|}{ Low SES } & \multicolumn{2}{|c|}{ High SES } & \multirow[b]{2}{*}{$p$-values } \\
\hline & $n$ & $\%$ & $n$ & $\%$ & $\mathrm{n}$ & $\%$ & \\
\hline Overall sample & 21,075 & & 8504 & & 12,571 & & \\
\hline \multicolumn{8}{|l|}{ Age categories } \\
\hline $15-19$ years & 2762 & 11.5 & 1242 & 12.3 & 1520 & 10.8 & $<0.001$ \\
\hline 20-24 years & 2578 & 12.4 & 1209 & 14.3 & 1369 & 11.0 & \\
\hline 25-49years & 9715 & 53.5 & 4021 & 54.9 & 5694 & 52.4 & \\
\hline $50+$ years & 6020 & 22.6 & 2032 & 18.6 & 3988 & 25.8 & \\
\hline \multicolumn{8}{|l|}{ Sex } \\
\hline Male & 8812 & 47.9 & 3556 & 47.6 & 5256 & 48.2 & 0.481 \\
\hline Female & 12,263 & 52.1 & 4948 & 52.4 & 7315 & 51.8 & \\
\hline \multicolumn{8}{|l|}{ Race } \\
\hline Black African & 13,747 & 79.0 & 7551 & 95.2 & 6196 & 66.1 & $<0.001$ \\
\hline White & 1509 & 9.3 & 24 & 0.4 & 1485 & 16.3 & \\
\hline Coloured & 3805 & 8.9 & 875 & 4.2 & 2930 & 12.6 & \\
\hline Indian/Asian & 2014 & 2.9 & 54 & 0.2 & 1960 & 5.0 & \\
\hline \multicolumn{8}{|l|}{ Current marital status } \\
\hline Married & 6758 & 29.2 & 1751 & 19.6 & 5007 & 36.8 & $<0.001$ \\
\hline Not married & 14,312 & 70.8 & 6752 & 80.4 & 7560 & 63.2 & \\
\hline \multicolumn{8}{|c|}{ Highest educational level obtained } \\
\hline No education/primary & 3278 & 16.8 & 1874 & 24.9 & 1404 & 10.9 & $<0.001$ \\
\hline Secondary & 10,263 & 67.6 & 3889 & 70.4 & 6374 & 65.5 & \\
\hline Tertiary & 2276 & 15.6 & 201 & 4.7 & 2075 & 23.6 & \\
\hline \multicolumn{8}{|l|}{ Employment status } \\
\hline Unemployed & 13,432 & 63.8 & 6053 & 71.7 & 7379 & 57.6 & $<0.001$ \\
\hline Employed & 7352 & 36.2 & 2355 & 28.3 & 4997 & 42.4 & \\
\hline \multicolumn{8}{|l|}{ Locality type } \\
\hline Urban & 13,810 & 69.5 & 3202 & 48.5 & 10,608 & 86.2 & $<0.001$ \\
\hline Rural informal (tribal areas) & 4909 & 25.8 & 3650 & 44.8 & 1259 & 10.8 & \\
\hline Rural (farms) & 2356 & 4.7 & 1652 & 6.7 & 704 & 3.1 & \\
\hline
\end{tabular}

uptake by asset-based socio-economic status among respondents aged 15 years and older. Among respondents from low SES households, females were significantly more likely to test for HIV [adjusted odds ratio $(\mathrm{aOR})=$ $3.21, p<0.001]$ than males. The increased likelihood of HIV testing uptake was significantly associated with respondents with secondary $[\mathrm{aOR}=1.58, p=0.026]$ and tertiary $[\mathrm{aOR}=3.63, p=0.017]$ level education, compared to those with no education or with primary level education completed. Those who used a condom at last sex were significantly more likely to test for HIV [aOR = 1.48, $p=0.028$ ] compared to those who did not use a condom. The decreased likelihood of HIV testing uptake was significantly associated with respondents who engaged in low-risk drinking $[\mathrm{OR}=0.62, p=0.028$ and high-risk drinking $[\mathrm{OR}=0.29, p=0.010]$ compared to those who abstained from alcohol. Respondents who perceived themselves as being at risk of HIV infection were also significantly less likely to test for HIV [OR = $0.67, p=0.029]$ than their counterparts. The decreased likelihood of HIV testing uptake was significantly associated with respondents who resided in rural formal areas $[\mathrm{OR}=0.61, p=0.032]$ compared to those from urban areas.

Among respondents from high SES households, females were significantly more likely to test for HIV $[\mathrm{aOR}=1.90, p<0.001]$ than males. The increased likelihood of HIV testing uptake was significantly associated with respondents with tertiary $[\mathrm{aOR}=2.09, p=0.033]$ level education, compared to those with no education or with primary level education completed. The decreased likelihood of HIV testing uptake was significantly 
Table 2 Socio-demographic characteristics and HIV testing by socio-economic status (SES) among youth and adults 15 years and older, South Africa 2017

\begin{tabular}{|c|c|c|c|c|c|c|c|}
\hline \multirow[t]{2}{*}{ Variable } & \multicolumn{2}{|l|}{ Total } & \multicolumn{2}{|c|}{ Low SES } & \multicolumn{3}{|c|}{ High SES } \\
\hline & $\mathrm{N}$ & Tested & $\mathrm{n}$ & Tested & $\mathrm{n}$ & Tested & $p$-value \\
\hline Overall & 21,075 & 75.4 & 8504 & 73.8 & 12,571 & 76.7 & $<0.001$ \\
\hline \multicolumn{8}{|l|}{ Age categories } \\
\hline 15-19years & 2762 & 41.9 & 1242 & 42.0 & 1520 & 41.9 & 0.958 \\
\hline 20-24 years & 2578 & 74.1 & 1209 & 73.2 & 1369 & 75.1 & 0.271 \\
\hline 25-49 years & 9715 & 85.2 & 4021 & 83.0 & 5694 & 87.1 & $<0.001$ \\
\hline $50+$ years & 6020 & 69.9 & 2032 & 68.2 & 3988 & 70.9 & 0.031 \\
\hline \multicolumn{8}{|l|}{ Sex of respondent } \\
\hline Male & 8812 & 71.2 & 3556 & 67.3 & 5256 & 74.2 & $<0.001$ \\
\hline Female & 12,263 & 79.4 & 4948 & 79.8 & 7315 & 79.0 & 0.283 \\
\hline \multicolumn{8}{|l|}{ Race } \\
\hline Black African & 13,747 & 76.7 & 7551 & 74.0 & 6196 & 79.7 & $<0.001$ \\
\hline White & 1509 & 69.7 & 24 & 64.5 & 1485 & 69.8 & 0.575 \\
\hline Coloured & 3805 & 74.1 & 875 & 71.6 & 2930 & 74.7 & 0.067 \\
\hline Indian/A & 2014 & 63.9 & 54 & 62.7 & 1960 & 64.0 & 0.844 \\
\hline \multicolumn{8}{|l|}{ Current marital status } \\
\hline Married & 6758 & 81.5 & 1751 & 80.5 & 5007 & 81.9 & 0.194 \\
\hline Not married & 14,312 & 72.9 & 6752 & 72.2 & 7560 & 73.7 & 0.044 \\
\hline \multicolumn{8}{|c|}{ Highest level of education obtained } \\
\hline No education/primary & 3278 & 71.9 & 1874 & 72.6 & 1404 & 70.7 & 0.232 \\
\hline Secondary & 10,263 & 80.4 & 3889 & 81.0 & 6374 & 80.0 & 0.216 \\
\hline Tertiary & 2276 & 86.1 & 201 & 89.1 & 2075 & 85.7 & 0.185 \\
\hline \multicolumn{8}{|l|}{ Employment status } \\
\hline Unemployed & 13,432 & 70.7 & 6053 & 71.0 & 7379 & 70.5 & 0.526 \\
\hline Employed & 7352 & 84.0 & 2355 & 81.3 & 4997 & 85.5 & $<0.001$ \\
\hline \multicolumn{8}{|l|}{ Locality type } \\
\hline Urban areas & 13,810 & 77.5 & 3202 & 78.7 & 10,608 & 77.0 & 0.044 \\
\hline Rural informal areas & 4909 & 70.5 & 3650 & 69.3 & 1259 & 74.7 & $<0.001$ \\
\hline Rural formal areas & 2356 & 71.1 & 1652 & 69.4 & 704 & 74.0 & 0.025 \\
\hline
\end{tabular}

associated with being White $[\mathrm{aOR}=0.37, p<0.001]$, Coloured $[\mathrm{aOR}=0.68, \quad p=0.052]$ and Indian/Asian $[\mathrm{aOR}=0.08, p<0.001]$ compared to being Black African. The decreased likelihood of HIV testing uptake was significantly associated with respondents who engaged in risky drinking $[\mathrm{OR}=0.51, p=0.019]$ and high-risk drinking $[\mathrm{OR}=0.31, p=0.046]$ compared to those who abstained from alcohol.

\section{Discussion}

This secondary analysis of 2017 nationally representative population-based study showed that people with a high socio-economic status reported significantly higher HIV testing uptake than those with a low SES, $76.7 \%$ vs $73.8 \%$. The differences in HIV testing between high and low SES were found in specific socio-demographic and
HIV-related risk characteristics. HIV testing uptake was higher among those aged $25-49$ years, males, Black Africans, the employed, and those residing in rural informal areas in high SES compared to low SES households. Furthermore, HIV testing uptake was higher among those aged 50 years and older, those not married, those residing in urban and rural formal areas in high SES compared to low SES households. In addition, HIV testing uptake was higher among high SES compared to low SES households and varied by sexual activity, age of sexual partner, alcohol consumption, correct HIV knowledge and myth rejection, self-perceived risk of HIV infection, and HIV serostatus. The observed differences occur against the background of policies and programs initiated to expand HIV testing by increasing the availability of quality HIV testing services (HTS) and its 
Table 3 HIV related risk characteristics and HIV testing by socio-economic status (SES) among youth and adults 15 years and older, South Africa 2017

\begin{tabular}{|c|c|c|c|c|c|c|c|}
\hline \multirow{2}{*}{$\begin{array}{l}\text { Variable } \\
\text { Sexual activity }\end{array}$} & \multicolumn{2}{|l|}{ Total } & \multicolumn{2}{|c|}{ Low SES } & \multicolumn{2}{|c|}{ High SES } & \multirow[b]{2}{*}{$p$-value } \\
\hline & $\bar{N}$ & $\overline{\text { Tested }}$ & $\bar{n}$ & $\overline{\text { Tested }}$ & $\bar{n}$ & $\overline{\text { Tested }}$ & \\
\hline Never had sex & 3142 & 42.3 & 1368 & 41.0 & 1920 & 45.1 & 0.019 \\
\hline Had sex & 15,741 & 81.2 & 6766 & 80.4 & 9895 & 82.1 & 0.006 \\
\hline \multicolumn{8}{|l|}{ Sexual debut } \\
\hline Sex before the age of 15 years & 324 & 67.4 & 169 & 65.6 & 173 & 69.5 & 0.441 \\
\hline Sex at 15 years and older & 4859 & 57.2 & 2269 & 58.0 & 2710 & 57.7 & 0.831 \\
\hline \multicolumn{8}{|l|}{ Age of sexual partner } \\
\hline Partner more than 5 years younger & 1971 & 82.2 & 2344 & 82.3 & 3908 & 85.2 & 0.002 \\
\hline Partner within five years & 5849 & 84.3 & 813 & 81.3 & 1179 & 83.2 & 0.274 \\
\hline Partner more than 5 years older & 2308 & 89.8 & 1073 & 90.3 & 1414 & 90.0 & 0.804 \\
\hline \multicolumn{8}{|c|}{ Number of sexual partners in the past 12 months } \\
\hline 1 sexual partner & 9289 & 85.2 & 3827 & 84.5 & 6024 & 85.7 & 0.102 \\
\hline $2+$ or more sexual partners & 892 & 82.5 & 438 & 79.4 & 504 & 86.2 & 0.006 \\
\hline \multicolumn{8}{|c|}{ Condom use at last sex in the past 12 months } \\
\hline No condom use & 6564 & 84.9 & 2445 & 83.8 & 4535 & 85.4 & 0.075 \\
\hline Yes condom use & 3541 & 85.0 & 1817 & 84.1 & 1919 & 86.3 & 0.058 \\
\hline \multicolumn{8}{|l|}{ AUDIT Score } \\
\hline Abstainers & 13,037 & 73.5 & 5974 & 72.9 & 7835 & 74.7 & 0.017 \\
\hline Low risk $(1-7)$ & 3537 & 77.9 & 1177 & 76.8 & 2532 & 78.7 & 0.193 \\
\hline Risky level (8-15) & 1257 & 79.2 & 557 & 76.2 & 761 & 81.4 & 0.022 \\
\hline High risk/harmful (16-19) & 209 & 74.9 & 113 & 68.8 & 112 & 81.5 & 0.028 \\
\hline High risk/hazardous (20+) & 226 & 70.6 & 135 & 68.7 & 104 & 72.9 & 0.480 \\
\hline \multicolumn{8}{|c|}{ Correct HIV knowledge and myth rejection } \\
\hline No knowledge & 12,575 & 74.1 & 5760 & 73.0 & 7518 & 75.5 & 0.001 \\
\hline Yes knowledge & 7337 & 77.1 & 2726 & 75.6 & 5034 & 78.6 & 0.003 \\
\hline \multicolumn{8}{|l|}{ Self-perceived risk of HIV infection } \\
\hline No risk & 15,921 & 72.3 & 6089 & 69.3 & 10,681 & 74.8 & $<0.001$ \\
\hline Yes risk & 2378 & 79.4 & 1363 & 78.2 & 1186 & 80.8 & 0.105 \\
\hline \multicolumn{8}{|l|}{ HIV serostatus } \\
\hline HIV Positive & 2358 & 87.6 & 1449 & 85.9 & 909 & 90.0 & 0.003 \\
\hline HIV Negative & 12,044 & 74.8 & 4889 & 72.7 & 7155 & 76.2 & $<0.001$ \\
\hline
\end{tabular}

uptake in all public health facilities in South Africa [30, 31]. These findings highlight the importance of implementing diversified modes of HIV testing with tailored strategies to increase uptake among people characterised by low SES. Demographic and socio-economic predictors of HIV testing uptake are important for this tailored targeting of varied approaches among different population groups.

Findings from the final multivariate logistic regression models showed that among low SES households, there is a need to target males, those with no education or low levels of educational attainment, those residing in rural formal or tribal areas, low risk and high-risk drinkers and low self-perceived risk of HIV infection. The observed higher levels of HIV testing among females is consistent with global statistics [32, 33]. In South Africa, antenatal services are widely available, and women commonly receive HIV tests in this setting [30]. On the other hand, men are less likely than women to use health services and take an HIV test [34]. This limited male participation in HIV testing is worrisome since those HIV positive men who are unaware of their status may continue to engage in unsafe behaviour [35]. Research evidence shows that men can be encouraged to test for HIV by other men through door-to-door testing campaigns 


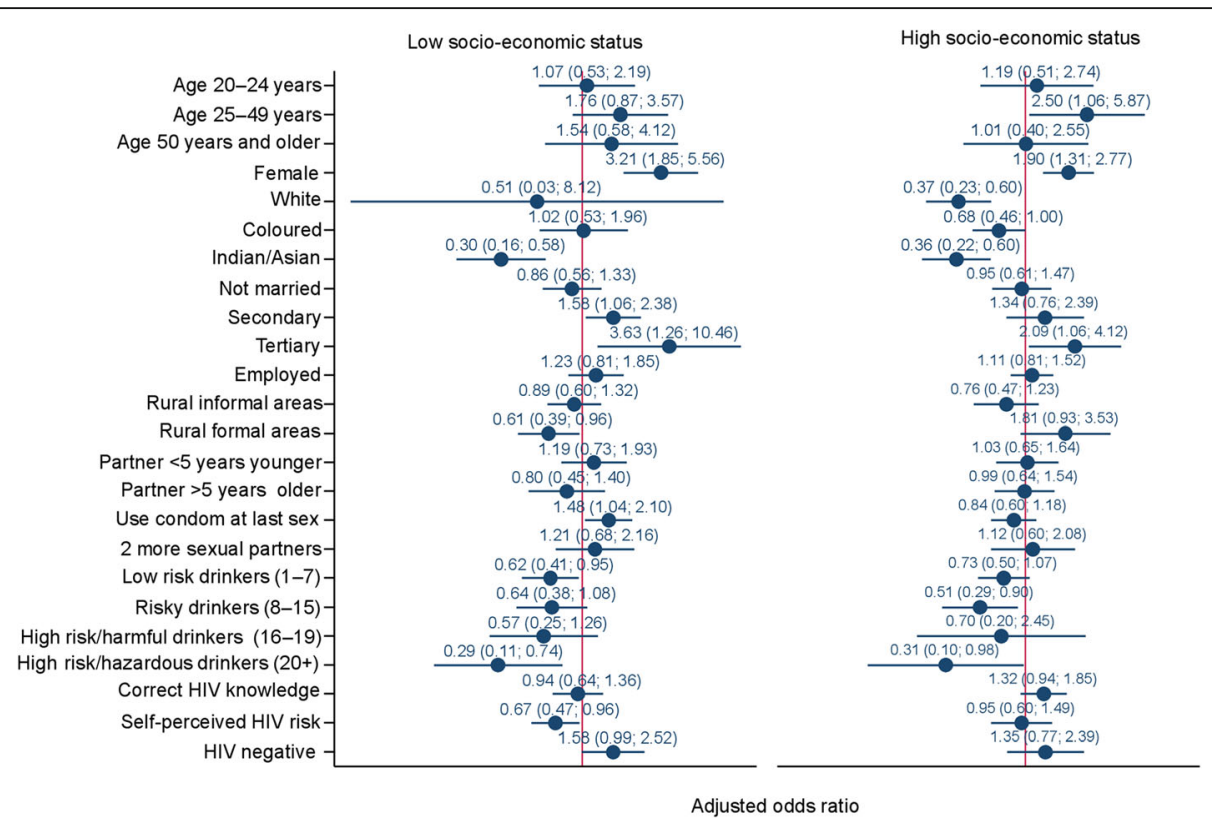

Fig. 1 Multivariate models of factors associated with HIV testing by socio-economic status among youth and adults 15 years and older, South Africa 2017

and health-care services targeted towards them [36]. HIV testing strategies that are more convenient and confidential, like community-based approaches and HIV self-testing, have increased HIV testing uptake among men [37, 38]. Other proposed strategies include social and cultural approaches that engage men as leaders (village chiefs and headmen) to promote an enabling environment to encourage health seeking behaviour and engagement in HTS [39].

Considering the evidence that educational attainment has been linked to increased HIV testing uptake [4043], existing Government measures to strengthen and improve access to universal education among predominantly lower SES groups is key to addressing differential HIV testing patterns. Implementing the piloted provision of HTS in schools and during the further education and training phase is key in bridging HIV testing disparities in the country [44]. In addition, health promotion efforts should intensify education programs on HIV and make full utilisation of HIV testing and counselling services appealing to those with the least education or no formal education [45].

The finding that uptake of HIV testing was less likely among those in rural areas with low SES could be linked to limited resources and structural barriers to health care in terms of geographical and financial accessibility [45]. This suggests a need to expand HIV testing beyond traditional centres for voluntary counselling and testing through outreach efforts, including mobile testing and home-based testing in impoverished rural communities [46-49].
Congruent with current findings, alcohol consumption has also been a barrier to prior HIV testing in a population-based study [50]. Since alcohol use is particularly problematic in impoverished communities, it is important to increase awareness and knowledge of HIV among population groups who drink alcohol excessively and clients of addiction health services. Communitybased HIV testing with facilitated linkage to care is also recommended for this group [51, 52]. These interventions should involve integrating substance and alcohol prevention components into national HIV awareness campaigns and screening and brief interventions for substance and alcohol use in HIV programs [52].

The association of low HIV testing uptake with a high self-perceived risk of HIV infection implies that individuals might refuse HIV testing even if they know that they are at high risk of HIV infection. This differs from the view that people who refuse HIV testing commonly do so because they do not perceive themselves to be at risk [53]. Nevertheless, awareness of HIV does not always translate to a perception of individual risk [54]. Self-perceived risk is an important factor in the uptake of HIV testing, and HIV testing campaigns should incorporate HIV risk perception assessments and interventions to correct false risk perception, encourage HIV testing uptake, and link individuals to care $[55,56]$.

The results from the high SES model showed that Whites and Indians/Asians were less likely to test for HIV than Black Africans. The observed racial differences in HIV testing can be attributed to the low selfperceived risk of HIV infection among minority groups. 
The promotion of HIV testing is an important component of primary and secondary HIV prevention strategies [30], yet little is known about the impact of missed opportunities for HIV testing and delayed presentation to HIV services among minority groups. There is, therefore, a need for population-based studies of HIV testing behaviours of minority groups in South Africa.

Consistent with other studies, our results found a positive association between HIV testing and condom use in low SES households $[57,58]$. Other studies found poor condom use, whether tested or not tested for HIV, indicating no association between condom use and HIV testing $[59,60]$. The current results are encouraging since condom use and uptake of HIV testing are key strategies for preventing HIV transmission. Despite the reported improvement in HIV testing uptake in the country, it is still unacceptably low among the youth and male population. Furthermore, consistent condom use remains relatively poor in the country [2]. Therefore, there is an urgent need for the National HIV programme to continue expanding efforts of scaling up HTS and promoting both correct and consistent condom use towards reducing HIV prevalence and incidence in South Africa.

The study has several limitations. The analysis is based on self-reported HIV testing and risk factors, which are prone to social desirability and recall bias. There has been some concern that the asset index has an urban bias as it is based on assets that capture social stratification better in urban than in rural settings, making rural asset households look poorer than they should [61, 62]. This suggests that the index may exaggerate the urban-rural differences. Furthermore, due to the cross-sectional design of the current study, causal inferences cannot be drawn, and the analysis is only limited to identifying associations. Despite these limitations, this study used a nationally representative sample, and the findings are generalisable to the entire country.

\section{Conclusions}

This study revealed that socio-economic inequalities in the uptake of HIV testing remain substantial in the country, despite more than a decade of the increasing availability of quality HTS. Social-demographic factors and HIV-related risk factors have an influence on the differential uptake of HIV testing by SES. The findings suggest diverse and targeted modes of HIV testing with interventions at the different socio-demographic and socio-economic levels focusing on their specific testing barriers to bridge the socio-economic gap in the uptake of HIV testing towards reaching the first 90 of the 90 90-90 targets in South Africa.

\section{Abbreviations}

AIDS: Acquired Immune Deficiency Syndrome; ART: Antiretroviral therapy; Cl: Confidence Interval; HIV: Human Immunodeficiency Virus; HTS: HIV testing services; MCA: Multiple correspondence analysis; SAL: Small area layer; SES: Socio-economic status; SSA: Sub-Saharan Africa; UNAIDS: Joint United Nations Programme on HIV/AIDS; VP: Visiting Point

\section{Acknowledgements}

Not applicable.

\section{Authors' contributions}

SJ drafted of the manuscript. SJ and MM performed the statistical analysis. SJ, MM, AN, YS, MT and LS participated in the implementation of the survey that provided the data for the manuscript. All authors contributed to the review of draft manuscript and approved the final manuscript.

\section{Authors' information}

Not applicable.

\section{Funding}

This manuscript was supported by the President's Emergency Plan for AIDS Relief (PEPFAR) through the Centers for Disease Control and Prevention, under the terms of Cooperative Agreement Number [NU2GGH001629]. The findings and conclusions in this report are those of the author(s) and do not necessarily represent the official position of the funding agencies.

\section{Availability of data and materials}

The datasets used and/or analysed during the current study are available from the corresponding author on reasonable request.

\section{Declarations}

Ethics approval and consent to participate

The survey protocol was approved by the HSRC Research Ethics Committee (REC: 4/18/11/15) and the Associate Director for Science, Center for Global Health, Centers for Disease Control and Prevention (CDC). Ethical clearance was also obtained from the University of KwaZulu-Natal's Biomedical Research Ethics Committee (BE 646/18). Informed consent was obtained before undertaking both the behavioural data and specimen collection. Participant interview privacy and confidentiality was protected through unique individual identifiers. This also included the use of linked anonymous blood testing with informed consent. All youth and adults who agreed to participate were required to provide written or verbal consent for cases where participants were illiterate and were unable to sign the consent form for themselves. Where such situations arose, an impartial witness would sign on behalf of the participant certifying that informed consent has been given verbally by the participant. The ethics committees approved the procedure for verbal consent. Guardians provided informed consent to allow their eligible children to be approached by the fieldworkers. Minors then provided their own assent to participate in the study.

Consent for publication

Not applicable.

\section{Competing interests}

The authors declare that they have no competing interests.

\section{Author details}

${ }^{1}$ Human and Social Capabilities Research Division, Human Sciences Research Council, 118 Buitengracht St, Cape Town City Centre, Cape Town 8000, South Africa. ${ }^{2}$ University of KwaZulu-Natal, School of Nursing and Public Health, 238 Mazisi Kunene Rd, Glenwood, Durban 4041, South Africa. ${ }^{3}$ Deputy CEO for Research, Human Sciences Research Council, 118 Buitengracht St, Cape Town City Centre, Cape Town 8000, South Africa. ${ }^{4}$ Department of Psychiatry \& Mental Health, University of Cape Town, Groote Schuur Dr, Observatory, Cape Town 7700, South Africa. 
Received: 6 October 2020 Accepted: 2 August 2021

\section{Published online: 26 August 2021}

\section{References}

1. UNAIDS. Miles to go. Global AIDS update. Geneva: Joint United Nations Programme on HIV/AIDS; 2018.

2. Simbayi LC, Zuma K, Zungu N, Moyo S, Marinda E, Jooste S, et al. South African national HIV prevalence, incidence, behaviour and communication survey, 2017. Cape Town: HSRC Press; 2019.

3. UNAIDS. The Gap Report. Geneva: Joint United Nations Programme on HIV/ AIDS: Joint United Nations Programme on HIV/AIDS; 2014.

4. Peltzer K, Matseke G, Mzolo T, Majaja M. Determinants of knowledge of HIV status in South Africa: results from a population-based HIV survey. BMC Public Health. 2009;9(1):174. https://doi.org/10.1186/1471-2458-9-174.

5. Musheke M, Ntalasha H, Gari S, McKenzie O, Bond V, Martin-Hilber A, et al. A systematic review of qualitative findings on factors enabling and deterring uptake of HIV testing in sub-Saharan Africa. BMC Public Health. 2013;13(1): 220. https://doi.org/10.1186/1471-2458-13-220.

6. Chemaitelly H, Cremin I, Shelton J, Hallett TB, Abu-Raddad LJ. Distinct HIV discordancy patterns by epidemic size in stable sexual partnerships in subSaharan Africa. Sex Transm Infect. 2012;88(1):51-7. https://doi.org/10.1136/ sextrans-2011-050114.

7. Jean K, Anglaret X, Moh R, Lert F, Dray-Spira R. Barriers to HIV testing in Côte d'Ivoire: the role of individual characteristics and testing modalities. PLoS One. 2012;7(7):e41353. https://doi.org/10.1371/journal.pone.0041353.

8. Obermeyer CM, Neuman M, Hardon A, Desclaux A, Wanyenze R, Ky-Zerbo $\mathrm{O}$, et al. Socio-economic determinants of HIV testing and counselling: a comparative study in four African countries. Tropical Med Int Health. 2013; 18(9):1110-8. https://doi.org/10.1111/tmi.12155.

9. Deblonde J, De Koker P, Hamers FF, Fontaine J, Luchters S, Temmerman M. Barriers to HIV testing in Europe: a systematic review. Eur J Pub Health. 2010;20(4):422-32. https://doi.org/10.1093/eurpub/ckp231.

10. Wabiri N, Taffa N. Socio-economic inequality and HIV in South Africa. BMC Public Health. 2013;13(1):1037. https://doi.org/10.1186/1471-2458-13-1037.

11. Goudge J, Gilson L, Russell S, Gumede T, Mills A. The household costs of health care in rural South Africa with free public primary care and hospital exemptions for the poor. Tropical Med Int Health. 2009;14(4):458-67. https:// doi.org/10.1111/j.1365-3156.2009.02256.x.

12. Lankowski AJ, Siedner MJ, Bangsberg DR, Tsai AC. Impact of geographic and transportation-related barriers on HIV outcomes in sub-Saharan Africa: a systematic review. AIDS Behav. 2014;18(7):1199-223. https://doi.org/10.1007/ s10461-014-0729-8.

13. Mohlabane N, Tutshana B, Peltzer K, Mwisongo A. Barriers and facilitators associated with HIV testing uptake in south African health facilities offering HIV counselling and testing. Health SA Gesondheid. 2016;21:86-95. https:// doi.org/10.1016/j.hsag.2015.11.001.

14. Nuwaha F, Kabatesi D, Muganwa M, Whalen CC. Factors influencing acceptability of voluntary counselling and testing for $\mathrm{HIV}$ in Bushenyi district of Uganda. East Afr Med J. 2002;79(12):626-32. https://doi.org/10.4314/eamj.v79i12.8669.

15. Wringe A, Isingo R, Urassa M, Maiseli G, Manyalla R, Changalucha J, et al. Uptake of HIV voluntary counselling and testing services in rural Tanzania: implications for effective HIV prevention and equitable access to treatment. Trop Med Int Health. 2008;13(3):319-27. https://doi.org/10.1111/j.1365-31 56.2008.02005.x

16. Bunyasi EW, Coetzee DJ. Relationship between socioeconomic status and HIV infection: findings from a survey in the Free State and Western cape provinces of South Africa. BMJ Open. 2017;7(11):e016232. https://doi.org/1 0.1136/bmjopen-2017-016232.

17. Festin K, Thomas K, Ekberg J, Kristenson M. Choice of measure matters: study of the relationship between socioeconomic status and psychosocial resources in a middle-aged normal population. PLoS One. 2017;12(8): e0178929. https://doi.org/10.1371/journal.pone.0178929.

18. Hayward MD, Hummer RA, Sasson I. Trends and group differences in the association between educational attainment and U.S. adult mortality: implications for understanding education's causal influence. Soc Sci Med. 2015;127:8-18. https://doi.org/10.1016/j.socscimed.2014.11.024.

19. Daly MC, Duncan GJ, McDonough P, Williams DR. Optimal indicators of socioeconomic status for health research. Am J Public Health. 2002;92(7): 1151-7. https://doi.org/10.2105/ajph.92.7.1151.

20. Singh-Manoux A, Clarke P, Marmot M. Multiple measures of socio-economic position and psychosocial health: proximal and distal measures. Int J
Epidemiol. 2002;31(6):1192-9; discussion 9-200. https://doi.org/10.1093/ ije/31.6.1192.

21. Avlund K, Holstein BE, Osler M, Damsgaard MT, Holm-Pedersen P, Rasmussen NK. Social position and health in old age: the relevance of different indicators of social position. Scand J Public Health. 2003;31(2):12636. https://doi.org/10.1080/14034940210134130.

22. Berg S, Burger R, von Maltitz M, Rand G. Using an asset index to assess trends in poverty in seven sub-Saharan African countries. World Dev. 2008; 36:1113-30.

23. Booysen F, van der Berg S, Burger R. Maltitz mv, Rand Gd. Using an asset index to assess trends in poverty in seven sub-Saharan African countries. World Dev. 2008;36(6):1113-30. https://doi.org/10.1016/j.worlddev.2007.10. 008.

24. Filmer D, Scott K. Assessing asset indices. Demography. 2012;49(1):359-92. https://doi.org/10.1007/s13524-011-0077-5.

25. StatsSA. Mid-year population estimates 2017. Pretoria: Statistics South Africa; 2017

26. Mthembu J, Mabaso M, Reis S, Zuma K, Zungu N. Prevalence and factors associated with intimate partner violence among the adolescent girls and young women in South Africa: findings the 2017 population based crosssectional survey. BMC Public Health. 2021;21(1):1160. https://doi.org/10.11 86/s12889-021-11183-Z.

27. Saunders JB, Aasland OG, Babor TF, De La Fuente JR, Grant M. Development of the alcohol use disorders identification test (AUDIT): WHO collaborative project on early detection of persons with harmful alcohol consumption-II. Addiction. 1993;88(6):791-804. https://doi.org/10.1111/j.1360-0443.1993.tb02 093.x.

28. Morojele NK, Nkosi S, Kekwaletswe CT, Shuper PA, Manda SO, Myers B, et al. Utility of brief versions of the alcohol use disorders identification test (AUDIT) to identify excessive drinking among patients in HIV Care in South Africa. J Stud Alcohol Drugs. 2016;78(1):88-96.

29. Jann B. Plotting regression coefficients and other estimates. Stata J. 2014; 14(4):708-37. https://doi.org/10.1177/1536867X1401400402.

30. NDOH. National HIV testing services: policy 2016. Pretoria: National Department of Health; 2016.

31. NDOH. Health sector HIV prevention strategy. Pretoria: National Department of Health; 2017.

32. WHO. Guideline on when to start antiretroviral therapy and on preexposure prophylaxis for HIV. Geneva: World Health Organization; 2015.

33. WHO. Global tuberculosis report 2019. Geneva: World Health Organization; 2019.

34. UNAIDS. Blind spot: reaching out to men and boys-Addreeing a blind spot in the HIV response to HIV. Geneva: Joint United Nations Programme on HIV/AIDS; 2017.

35. Mills EJ, Beyrer C, Birungi J, Dybul MR. Engaging men in prevention and care for HIV/AIDS in Africa. PLoS Med. 2012;9(2):e1001167. https://doi.org/1 0.1371/journal.pmed.1001167.

36. UNAIDS. A snapshot of men and HIV in South Africa. Geneva: Joint United Nations Programme on HIV/AIDS; 2017.

37. Hlongwa M, Mashamba-Thompson T, Makhunga S, Hlongwana K. Mapping evidence of intervention strategies to improving men's uptake to HIV testing services in sub-Saharan Africa: a systematic scoping review. BMC Infect Dis. 2019;19(1):496. https://doi.org/10.1186/s12879-019-4124-y.

38. Truong H-HM, Mocello AR, Ouma D, Bushman D, Kadede K, Ating'a E, et al. Community-based HIV testing services in an urban setting in western Kenya: a programme implementation study. Lancet HIV. 2021;8(1):e16-23. https://doi.org/10.1016/S2352-3018(20)30253-8.

39. Conserve DF, Issango J, Kilale AM, Njau B, Nhigula P, Memiah P, et al. Developing national strategies for reaching men with HIV testing services in Tanzania: results from the male catch-up plan. BMC Health Serv Res. 2019; 19(1):317. https://doi.org/10.1186/s12913-019-4120-3.

40. Tenkorang EY, Owusu GA. Correlates of HIV testing among women in Ghana: some evidence from the demographic and health surveys. AIDS Care. 2010;22(3):296-307. https://doi.org/10.1080/09540120903193716.

41. Hutchinson PL, Mahlalela X. Utilization of voluntary counseling and testing services in the Eastern Cape, South Africa: Taylor \& Francis; 2006. 2006/07/ 01. Report No.: 0954-0121 Contract No.: 5

42. Venkatesh KK, Madiba P, De Bruyn G, Lurie MN, Coates TJ, Gray GE. Who gets tested for HIV in a south African urban township? Implications for test and treat and gender-based prevention interventions. J Acquir Immune Defic Syndr. 2011;56(2):151-65. https:/doi.org/10.1097/QAl.0b013e318202c82c. 
43. Jukes M, Simmons S, Bundy D. Education and vulnerability: the role of schools in protecting young women and girls from HIV in southern Africa. AIDS. 2008;22(Suppl 4):S41-56. https://doi.org/10.1097/01.aids.0000341776. 71253.04.

44. Sambah F, Baatiema L, Appiah F, Ameyaw EK, Budu E, Ahinkorah BO, et al. Educational attainment and HIV testing and counselling service utilisation during antenatal care in Ghana: analysis of demographic and health surveys. PLoS One. 2020;15(1):e0227576. https://doi.org/10.1371/journal. pone.0227576.

45. Madiba S, Mokgatle M. Parents support implementation of HIV testing and counseling at school: cross-sectional study with parents of adolescent attending high School in Gauteng and North West Provinces, South Africa. AIDS Res Treat. 2016;2016:4842814.

46. Bassett IV, Walensky RP. Integrating HIV screening into routine health care in resource-limited settings. Clin Infect Dis. 2010;50(Suppl 3):S77-84.

47. Sharma M, Ying R, Tarr G, Barnabas R. Systematic review and meta-analysis of community and facility-based HIV testing to address linkage to care gaps in sub-Saharan Africa. Nature. 2015;528(7580):S77-85. https://doi.org/10.103 8/nature16044.

48. Suthar AB, Ford N, Bachanas PJ, Wong VJ, Rajan JS, Saltzman AK, et al. Towards universal voluntary HIV testing and counselling: a systematic review and meta-analysis of community-based approaches. PLoS Med. 2013;10(8):e1001496. https://doi.org/10.1371/journal.pmed.1 001496.

49. Hensen B, Taoka S, Lewis JJ, Weiss HA, Hargreaves J. Systematic review of strategies to increase men's HIV-testing in sub-Saharan Africa. Aids. 2014; 28(14):2133-45. https://doi.org/10.1097/QAD.0000000000000395.

50. Fatch R, Bellows B, Bagenda F, Mulogo E, Weiser S, Hahn JA. Alcohol consumption as a barrier to prior HIV testing in a population-based study in rural Uganda. AIDS Behav. 2013;17(5):1713-23. https://doi.org/10.1007/s104 61-012-0282-2.

51. Branson BM, Handsfield HH, Lampe MA, Janssen RS, Taylor AW, Lyss SB, et al. Revised recommendations for HIV testing of adults, adolescents, and pregnant women in health-care settings. MMWR Recomm Rep. 2006;55(Rr14):1-17 quiz CE1-4.

52. Kresina TF, Lubran R. The linkage of illicit drug use / alcohol use and HIV infection in young adults. Int J High Risk Behav Addict. 2017;6(1):e32129.

53. Takahashi TA, Johnson KM, Bradley KA. A population-based study of HIV testing practices and perceptions in 4 U.S. states. J Gen Intern Med. 2005; 20(7):618-22. https://doi.org/10.1111/j.1525-1497.2005.0112.x.

54. Clifton S, Nardone A, Field N, Mercer CH, Tanton C, Macdowall W, et al. HIV testing, risk perception, and behaviour in the British population. Aids. 2016; 30(6):943-52. https://doi.org/10.1097/QAD.0000000000001006.

55. Pringle K, Merchant RC, Clark MA. Is self-perceived HIV risk congruent with reported HIV risk among traditionally lower HIV risk and prevalence adult emergency department patients? Implications for HIV testing. AIDS Patient Care STDs. 2013;27(10):573-84. https://doi.org/10.1089/apc.2013.0013.

56. Khawcharoenporn T, Mongkolkaewsub S, Naijitra C, Khonphiern W, Apisarnthanarak A, Phanuphak N. HIV risk, risk perception and uptake of HIV testing and counseling among youth men who have sex with men attending a gay sauna. AIDS Res Ther. 2019;16(1):13. https://doi.org/10.1186/ s12981-019-0229-z.

57. Armstrong G, Medhi GK, Kermode M, Mahanta J, Goswami P, Paranjape RS Exposure to HIV prevention programmes associated with improved condom use and uptake of HIV testing by female sex workers in Nagaland, Northeast India. BMC Public Health. 2013;13(1):476. https://doi.org/10.11 86/1471-2458-13-476.

58. Agha S. Factors associated with HIV testing and condom use in Mozambique: implications for programs. Reprod Health. 2012;9(1):20. https://doi.org/10.1186/1742-4755-9-20.

59. Mhlongo S, Dietrich J, Otwombe KN, Robertson G, Coates TJ, Gray G. Factors associated with not testing for HIV and consistent condom use among men in Soweto, South Africa. PLoS One. 2013;8(5):e62637. https:// doi.org/10.1371/journal.pone.0062637.

60. Wang C, Hawes SE, Gaye A, Sow PS, Ndoye I, Manhart LE, et al. HIV prevalence, previous HIV testing, and condom use with clients and regular partners among Senegalese commercial sex workers. Sex Transm Infect. 2007;83(7):534-40. https://doi.org/10.1136/sti.2007.027151

61. Howe LD, Galobardes B, Matijasevich A, Gordon D, Johnston D, Onwujekwe $\mathrm{O}$, et al. Measuring socio-economic position for epidemiological studies in low- and middle-income countries: a methods of measurement in epidemiology paper. Int J Epidemiol. 2012;41(3):871-86. https://doi.org/10.1 093/ije/dys037.

62. Wittenberg M, Leibbrandt M. Measuring inequality by asset indices: a general approach with application to South Africa. Rev Income Wealth. 2017;63(4):706-30. https://doi.org/10.1111/roiw.12286.

\section{Publisher's Note}

Springer Nature remains neutral with regard to jurisdictional claims in published maps and institutional affiliations.
Ready to submit your research? Choose BMC and benefit from:

- fast, convenient online submission

- thorough peer review by experienced researchers in your field

- rapid publication on acceptance

- support for research data, including large and complex data types

- gold Open Access which fosters wider collaboration and increased citations

- maximum visibility for your research: over $100 \mathrm{M}$ website views per year

At BMC, research is always in progress.

Learn more biomedcentral.com/submissions 